\title{
Charles Baudelaire, Le Fior dël Mal - I Fiori del Male
}

\section{Mario Richter}

\section{OpenEdition}

\section{Journals}

\section{Edizione digitale}

URL: https://journals.openedition.org/studifrancesi/26658

DOI: 10.4000/studifrancesi.26658

ISSN: 2421-5856

\section{Editore}

Rosenberg \& Sellier

\section{Edizione cartacea}

Data di pubblicazione: 1 avril 2007

Paginazione: 205

ISSN: 0039-2944

\section{Notizia bibliografica digitale}

Mario Richter, "Charles Baudelaire, Le Fior dël Mal - I Fiori del Male», Studi Francesi [Online], 151 (LI | I) | 2007, online dal 30 novembre 2015, consultato il 23 novembre 2021. URL: http://

journals.openedition.org/studifrancesi/26658 ; DOI: https://doi.org/10.4000/studifrancesi.26658

Questo documento è stato generato automaticamente il 23 novembre 2021.

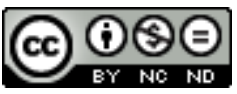

Studi Francesi è distribuita con Licenza Creative Commons Attribuzione - Non commerciale - Non opere derivate 4.0 Internazionale. 


\title{
Charles Baudelaire, Le Fior dël Mal - I Fiori del Male
}

\author{
Mario Richter
}

\section{NOTIZIA}

CHARLES BAUDELAIRE, Le Fior dël Mal - I Fiori del Male, Prefazione di Albina Malerba, Tradussion an Piemontèis ëd Rino dij Sèra (Rino Serra), Poirino, Comune di Poirino, 2005., pp. 206.

Per quanto possa apparire stravagante l'idea di trasporre in piemontese (con tanto di versi e rime) il maggiore libro poetico di Baudelaire, riteniamo che questa traduzione meriti di essere segnalata, non soltanto perché è un'ulteriore testimonianza della crescente gloria e persino della popolarità della poesia di Baudelaire, ma soprattutto perché il traduttore ha attuato la sua impegnativa impresa con una indubbia serietà e consapevolezza filologica. Si tratta infatti di una traduzione di encomiabile qualità, intimamente fedele all'originale, capace di raggiungere effetti di notevole efficacia propriamente poetica. Nella nutritissima serie delle traduzioni baudelairiane, questa ci sembra occupare, pur nei limiti inevitabili dell'idioma usato, un posto di tutto rispetto. 